\section{Call for slice of sugar tax revenue to help oral health}

By Adrian O'Dowd

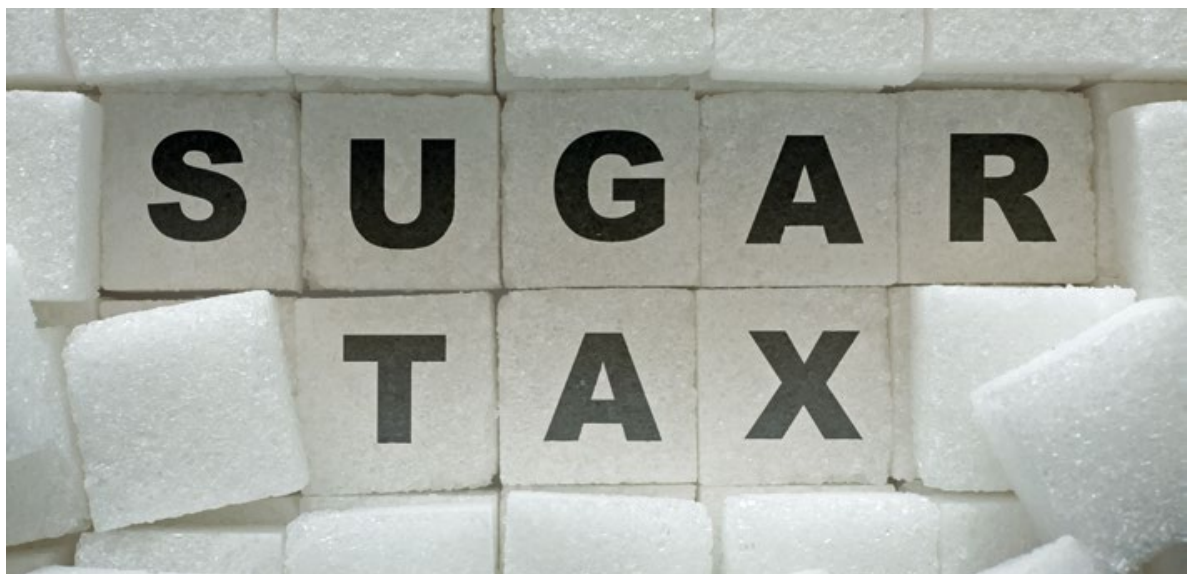

$\mathrm{D}$ ental and local government leaders are calling for some of the money gathered from the soft drinks industry levy - known as the sugar tax - in its first year to be spent on boosting oral health.

It has been estimated that around $£ 250$ million has been raised from the levy on sugar-sweetened drinks since it came into force in April 2018 - money which has been gathered by HMRC (HM Revenue \& Customs).

The BDA has now urged government and local authorities to step up their efforts to fight tooth decay through cost-effective programmes such as supervised brushing in nurseries helped by this new revenue.

The Association said it had estimated that a mere $2 \%$ of current revenues would be sufficient to bring supervised tooth brushing programmes to five-year-old children in the greatest need.

So far, no specific revenue from the levy has been earmarked to combat tooth decay and changes to how the sugar levy operates will come into effect this financial year with no Capital Fund available.

高 This means that revenues raised could merge into schools' daily spend with little oversight and the BDA is concerned that funds could be used for routine maintenance and repairs rather than any specific spending on worthwhile preventative steps such as oral ๑) health programmes.
Modelling ${ }^{1}$ by Public Health England has shown that interventions in deprived areas could yield significant returns on investment. The figures show $£ 1$ spent on supervised tooth brushing programmes in nurseries and primary schools would yield a $£ 3.06$ return in five years, rising to $£ 3.66$ in ten, as a result of reduced treatment costs.

Official estimates show targeting the most deprived fifth of five-year-olds in England would generate expected savings, after five years of the programme, of nearly $£ 10$ million.

Official data shows an $18 \%$ increase in the number of extractions taking place in children in hospitals since 2012, costing the NHS $£ 205$ million, so the need for action was clear, said the BDA.

Scotland and Wales had dedicated national child oral health programmes, operating in both nurseries and primary schools built around supervised tooth brushing, but England's equivalent - the Starting Well programme - was only operating in 13 local authorities with no new money attached.

BDA Chair Mick Armstrong said: 'Sugar is fuelling an epidemic of decay, and it's only right some of this windfall is used to make good on the damage.

'A tiny fraction of this revenue could transform the oral health of children in our most deprived communities. We shouldn't be spending millions on extractions, when tried and tested policies can make a lasting difference.

'Supervised toothbrushing is a winning investment, that the government's own models show will yield clear returns for our children's health and an overstretched NHS. The levy proceeds were meant to be put to work on prevention. Dentists have seen what works, and the funds are at hand.'

The Local Government Association (LGA), which said it estimated that producers had paid around $£ 250$ million in the first year towards the sugar tax, also supported action on encouraging good oral health.

It said children's health would be better protected if money raised from the levy went towards protecting and improving children's oral health, providing early years play equipment and activities, while also encouraging healthier eating and exercise to combat child obesity.

Currently, funding from the levy went towards school sports and breakfast clubs, but instead of the levy sitting outside of the public health system (something that councils are responsible for), it should be part of a joined-up approach with schools to tackling obesity and physical activity, said the LGA.

Chairman of the LGA's Community Wellbeing Board, Ian Hudspeth, said: 'In a year since the soft drinks industry levy was introduced, manufacturers have cut the amount of sugar in their products while hundreds of millions of pounds have been raised in revenue.

'It is vital that the funds raised so far are invested in the best possible way to ensure that our children get the greatest start in life.

'Councils need to be able to use this money to intervene earlier and do more to ensure that our children stay healthy, active and develop good eating habits, which they can continue into adulthood.

'Giving councils a say in deciding where the revenue from the soft drinks levy is spent will help lead to better, more innovative oral health education so that parents and children are supported to understand the impact of sugar on teeth and the importance of good oral hygiene.'

\section{References}

1. Public Health England. Return on investment of oral health improvement programmes for 0-5 year olds. 2019. Available at https://assets.publishing.service.gov.uk/government/ uploads/system/uploads/attachment_data/file/560973/ ROI_oral_health_interventions.pdf (accessed April 2019). 